\title{
GAMBARAN PERAN SUAMI DALAM PARTISIPASI K1 DAN K4 IBU HAMIL DI DESA CIKUNIR TAHUN 2017
}

\author{
Fenty Agustini, SST., M.Kes ${ }^{1}$ \\ Fentyagustini86@gmail.com \\ Gitri Andeyani \\ Sekolah Tinggi Ilmu Kesehatan (STIKes) Respati
}

\section{A. ABSTRAK}

Akses pelayanan ibu hamil pada kunjungan pemeriksaan kehamilan dari 36.168 orang ibu hamil yang ada di Kabupaten Tasikmalaya pada tahun 2015, telah melakukan pemeriksaan kehamilan pada kunjungan pertama (K1) sebesar 101,03\% dan kunjungan berikutnya (K4) sebesar $87,4 \%$. terjadi kenaikan yang signifikan apabila dibandingkan dengan tahun 2014 dari 90,9 menjadi 101,03\% untuk K1 sedangkan untuk K4 sebesar 9,5\% (77,9\% menjadi 87,4\%). Berdasarkan data pendahuluan di Puskesmas Singaparna Tahun 2016 data tentang kunjungan K1 yaitu sebesar 92,76\% dan kunjungan K4 sebesar 80,30\% data ini masih rendah dari cakupan Kabupaten Tasikmalaya.

Tujuan Penelitian ini adalah untuk mengetahui gambaran dukungan suami dalam partisipasi kunjungan K1 dan K4 pada ibu hamil di Desa Cikunir Tahun 2017. Jenis penelitian ini adalah deskriptif. Populasi dalam penelitian ini adalah seluruh ibu hamil yang melakukan kunjungan Antenatal Care di Desa Cikunir pada saat penelitian sebesar 26 orang dengan sampel total populasi yaitu sebanyak 26 orang.

Penelitian dengan analisa univariat didapatkan hasil sebanyak 18 responden $(69,23 \%)$ yang kurang mendapatkan dukungan dari suami dan terdapat $8(30,77 \%)$ yang mendapat dukungan dari suami. Saran bagi petugas kesehatan di Desa Cikunir untuk lebih meningkatkan promosi kesehatan tentang pentingnya kunjungan antenatal care bagi ibu hamil dan memberikan informasi kepada keluarga tentang bentuk dukungan yang harus diberikan kepada ibu hamil melalui komunikasi interpersonal saat suami mengantar ibu melakukan Antenatal Care ataupun memanfaatkan kader yang memiliki ikatan psikologis lebih dekat dengan masyarakat untuk melakukan kunjungan rumah dalam rangka mensosialisasikan peran suami dalam mendukung keberhasilan Antenatal Care pada ibu hamil.

Kata Kunci : dukungan suami, kunjungan antenatal care 


\section{B. LATAR BELAKANG}

Kehamilan adalah penyatuan dari spermatozoa dan ovum dan dilanjutkan dengan nidasi atau implantasi. Bila dihitung dari fase fertilitas hingga lahirnya bayi, kehamilan normal akan berlangsung dalam waktu 40 minggu atau 10 bulan lunar atau 9 bulan menurut kalender internasional. Kehamilan berlangsung dalam tiga trimester, trimester satu berlangsung dalam 13 minggu, trimester kedua 14 minggu (minggu ke-14 hingga ke-27), dan trimester ketiga 13 minggu (minggu ke-28 hingga ke-40) (Astuti, 2012). Menurut World Healt Organization (2010), Indonesia menduduki peringkat pertama dengan Angka Kematian Ibu (AKI) tertinggi dari 181 negara. Perdarahan menempati persentase tertinggi penyebab kematian ibu (28\%), anemia dan kurang energi kronik pada ibu hamil menjadi penyebab utama terjadinya perdarahan dan infeksi yang merupakan faktor utama kematian pada ibu hamil (Astuti, 2012). Penyebab kematian ibu di Indonesia yang utama adalah perdarahan (28\%), eklampsia (13\%), komplikasi aborsi $(11 \%)$, sepsis $(10 \%)$ dan partus lama $(9 \%)$. Penyebab itu sebenarnya dapat dicegah dengan pemeriksaan kehamilan yang memadai. Dengan melaksanakan Antenatal Care secara teratur pada ibu hamil diharapkan mampu mendeteksi dini dan menangani komplikasi yang sering terjadi pada ibu hamil, sehingga hal ini penting untuk menjamin bahwa proses alamiah dari kehamilannya berjalan dengan normal (Astuti, 2012). WHO memperkirakan bahwa sekitar 15\% dari seluruh wanita yang hamil akan berkembang menjadi komplikasi yang berkaitan dengan kehamilannya serta dapat dicegah melalui pemberian asuhan kehamilan yang berkualitas (Astuti, 2012). Manusia pada dasarnya selalu ingin tahu yang benar, untuk memenuhi rasa ingin tahu ini, manusia sejak jaman dahulu telah berusaha mengumpulkan pengetahuan.
Pengetahuan pada dasarnya terdiri dari sejumlah fakta dan teori yang memungkinkan seseorang untuk dapat memecahkan masalah yang dihadapinya. Pengetahuan tersebut diperoleh baik dari pengalaman langsung maupun melalui pengalaman orang lain (Notoatmodjo, 2010). Menurut World Health Organization (WHO), kematian maternal ialah kematian seorang wanita waktu hamil atau dalam 42 hari sesudah berakhirnya kehamilan oleh sebab apapun, terlepas dari tuanya kehamilan dan tindakan yang dilakukan untuk mengahiri kehamilan. Angka kematian yang tinggi setengah abad yang lalu umumnya mempunyai dua sebab pokok yaitu, masih kurangnya pengetahuan mengenai sebab-sebab dan penaggulangan komplikasi-komplikasi penting dalam kehamilan, persalinan, serta nifas. Kurangnya pengertian dan pengetahuan mengenai kesehatan reproduksi, dan kurang meratanya pelayanan kebidanan yang baik bagi semua yang hamil (Sulistyawati, 2009). Kurangnya dukungan suami untuk menstimulasi ibu agar teratur melakukan kunjungan Antanatal Care menyebabkan rendahnya partisipasi ibu dalam melakukan kunjungan kehamilan. Hasil penelitian survey kesehatan ibu pendekatan kemitraan dan keluarga tahun 2008 di 10 kabupaten di Provinsi Jawa Tengah dan Jawa Timur didapatkan ibu hamil yang tidak teratur melakukan kunjungan Antenatal Care sebanyak 10\% dari 14.000 ibu hamil, sebesar $60 \%$ ibu yang tidak melakukan Antenatal Care secara teratur tidak mendapatkan dukungan suami (Sulistyawati, 2009). Berdasarkan data profil dinas kesehatan Kabupaten Tasikmalaya pemeriksaan kehamilan pada kunjungan pertama (K1) sebesar 101,03\% dan kunjungan berikutnya (K4) sebesar $87,4 \%$. terjadi kenaikan yang signifikan apabila dibandingkan dengan tahun 2014 dari 90,9 menjadi 101,03\% untuk K1 sedangkan 
untuk K4 sebesar 9,5\% (77,9\% menjadi $87,4 \%)$. Berdasarkan data pendahuluan di Puskesmas Singaparna Tahun 2016 data tentang kunjungan K1 yaitu sebesar 92,76\% dan kunjungan K4 sebesar 80,30\% data ini masih rendah dari cakupan Kabupaten Tasikmalaya. Berdasarkan latar belakang tersebut penelitit tertarik untuk melakukan penelitian dengan judul Gambaran Peran Suami dalam Partisipasi K1 dan K4 Ibu Hamil di Desa Cikunir Tahun 2017.

\section{METODE PENELITIAN}

Jenis penelitian ini adalah deskriptif yaitu menggambarkan peran suami dalam partisipasi K1 dan K4 ibu hamil Populasi dalam penelitian ini adalah seluruh ibu hamil yang melakukan kunjungan Antenatal Care di Desa Cikunir pada saat penelitian sebesar 26 orang dengan sampel total populasi yaitu sebanyak 26 orang. Penelitian dilakukan di Desa Cikunir Kecamatan Singaparna Kabupaten Tasikmalaya. Teknik pengumpulan data dilakukan dengan data primer dan dilakukan analisis univariat yaitu menggambarkan peran suami dalam partisipasi kunjungan K1 dan K4 pada ibu hamil.

\section{HASIL PENELITIAN \\ a. Karakteristik Responden}

a) Pendidikan

Tabel 1 Karakteristik Responden Berdasarkan Pendidikan

\begin{tabular}{lccc}
\hline No & Pendidikan & Frek & $(\mathbf{\% )}$ \\
\hline 1 & Dasar & 23 & 88,46 \\
2 & Tinggi & 3 & 11,54 \\
\hline & Jumlah & 26 & 100 \\
\hline
\end{tabular}

Berdasarkan tabel 1 didapatkan bahwa sebagian besar responden memiliki pendidikan dasar yaitu sebanyak $88,46 \%$. b) Status Ekonomi

Tabel 2 Karakteristik Responden Berdasarkan Status Ekonomi

\begin{tabular}{lccc}
\hline No & Pendidikan & Frek & (\%) \\
\hline 1 & Dibawah & 18 & 69,23 \\
& UMR & & 30,77 \\
& $\begin{array}{c}\text { Diatas } \\
\text { UMR }\end{array}$ & 8 & 100 \\
\hline & Jumlah & 26 & 100 \\
\hline
\end{tabular}

Berdasarkan tabel 2 didapatkan bahwa sebagian besar responden memiliki penghasilan dibawah UMUR yaitu sebanyak $69,23 \%$.

\section{b. Hasil Penelitian}

a) Dukungan Suami

Tabel 3 Dukungan Suami

\begin{tabular}{lccc}
\hline No & Pendidikan & Frek & (\%) \\
\hline 1 & Kurang & 18 & 69,23 \\
& Mendukung & & \\
2 & Mendukung & 8 & 30,77 \\
\hline & Jumlah & 26 & 100 \\
\hline
\end{tabular}

Berdasarkan tabel 3 didapatkan bahwa sebagian besar responden memiliki tidak memiliki dukungan dari suami yaitu sebanyak 69,23\%.

\section{E. PEMBAHASAN}

Dukungan suami sebagian besar pada kategori kurang mendukung sebesar 18 responden atau $(69,23 \%)$. Hasil ini sejalan dengan penelitian juwita pada tahun 2003 di wilayah puskesmas kasihan II bantul Yogyakarta yang menyatakan ibu yang tidak mendapat dukungan suami dalam pelaksanaan Antenatal Care lebih dominan (78,4\%). Menurut Silvia (2008) dukungan anggota keluarga berupa dorongan, memberikan semangat dan inspirasi, memperlihatkan kepercayaan pada perbaikan prilaku kesehatan. Dukungan diberikan setelah anggota mengetahui tujuan dari dukungan yang diberikan dan mengetahui bentuk dukungan yang akan diberikan. Menurut peneliti diketahui bahwa 
dukungan suami sebagian besar pada kategori kurang mendukung untuk melakukan kunjungan ibu K1 dan K4 di Desa Cikunir Tahun 2017 disebabkan karena suami juga tidak mengetahui tujuan, manfaat dan waktu Antenatal Care. Rendahnya pengetahuan suami tentang tujuan Antenatal Care dimanifestasikan kedalam tindakan suami tidak memotivasikan ibu melakukan kunjungan Antenatal Care secara teratur, tidak menganjurkan ibu melakukan kunjungan Antenatal Care, tidak mengantar ibu melakukan kunjungan Antenatal Care, tidak mencarikan informasi manfaat Antenatal Care dan tidak memberikan pujian jika ibu melakukan kunjungan secara teratur. Hal ini dapat menjadi faktor predisposisi secara tidak langsung suami tidak mendukung ibu dalam melakukan Antenatal Care baik dukungan emosional, fisik, informasi maupun penghargaan. Begitupun sebaliknya ibu yang mendapat dukungan suami karena suami telah mengetahui manfaat dari Antenatal Care yang dimanifestasikan kedalam prilaku memberikan dukungan secara emosional dengan cara memotivasi ibu melakukan kunjungan Antenatal Care, memberikan dukungan fisik dengan mengantar ibu melakukan kunjungan Antenatal Care, memberikan dukungan informasi dengan cara mencarikan ibu informasi tentang manfaat, waktu dan kerugian jika tidak melakukan Antenatal Care serta memberikan dukungan penghargaan jika ibu tertur melakukan kunjungan Antenatal Care. Menurut Friedman (2006) keluarga berfungsi untuk melaksanakan praktek asuhan kesehatan, yaitu mencegah terjadinya gangguan kesehatan pada anggota keluarga.Kemampuan keluarga dalam memberikan asuhan kesehatan mempengaruhi status kesehatan keluarga. Begitu besarnya peran keluarga dalam merawat dan memelihara kesehatan bayi dan ibu hamil peran petugas kesehatan sangat signifikan untuk mensosialisasikan pentingnya melakukan Antenatal Care pada masa kehamilan terhadap keluarga terutama suami agar memberikan dukungan kepada istri untuk teratur melakukan kunjungan Antenatal Care. Menurut Sibuea
(2003) faktor-faktor yang mempengaruhi kunjungan Antenatal Care di antara karateristik ibu meliputi pendidikan, umur, dan status pekerjaan. Menurut Depkes (2001) faktor-faktor yang berpengaruh terhadap kunjungan Antenatal Care pada ibu hamil diantaranya meliputi adalah faktor pengetahuan, dukungan suami, pendidikan, setatus pekerjaan, dan paritas. Menurut beberapa suami meskipun tidak teratur melakukan Antenatal Care pada anak-anak sebelumnya terbukti bahwa anak-anak tersebut tidak mengalami gangguan dalam kesehatan baik saat kehamilan ataupun persalinan. Berdasarkan hasil penelitian bahwa sebagian besar ibu memiliki latar belakang pendidikan Dasar atau maksimal pendidikan SMA. Pendidikan rendah akan mempengaruhi kemampuan ibu untuk menangkap informasi dan materi baru yag disampaikan oleh petugas kesehatan tenang Antenatal Care, hasil penelitian responden dengan pendidikan rendah susah untuk memahami materi yang disampaikan oleh petugas kesehatan sehingga tidak memiliki pengetahuan yang cukup baik tetang kunjungan Antenatal Care yang pada akhirnya dapat mempengaruhi prilaku untuk tidak teratur melakukan Antenatal Care. Menurut Muhaimin (2004) orang dengan pendidikan formal yang lebih rendah cenderung akan mempunyai pengetahuan yang lebih rendah, karena kurang mampu dan sulit memahami arti dan pentingnya kesahatan dan ganguan-ganguan kesehatan yang mungkin terjadi sehingga berpengaruh untuk menerapkan pengetahuan tersebut dalam praktek kesehatan personal, informasi baru dan penerimaan kosep baru.

\section{F. SIMPULAN DAN SARAN \\ a. Simpulan}

Berdasarkan hasil penelitian didapatkan hasil bahwa sebagian besar ibu hamil tidak mendapatkan dukungan dari suami untuk melakukan kunjungan K1 dan K4 yaitu sebesar $69,23 \%$.

\section{b. Saran}

Saran bagi petugas kesehatan di Desa Cikunir untuk lebih meningkatkan promosi 
kesehatan tentang pentingnya kunjungan antenatal care bagi ibu hamil dan memberikan informasi kepada keluarga tentang bentuk dukungan yang harus diberikan kepada ibu hamil melalui komunikasi interpersonal saat suami mengantar ibu melakukan Antenatal Care.

\section{G. REFERENSI}

Astuti, Haturi Puji, 2012. Buku ajar asuhan kebidanan ibu 1 (kehamilan). Yogyakarta. Rohima Pres

Depkes RI. Profil kesehatan Indonesia 2001 Menuju Indonesia sehat 2010. Jakarta: Departemen Kesehatan RI. 2002:40.

Friedman, Howard S. \& Schustack, Miriam W. (2006). Kepribadian Teori Klasik dan Riset Modern Edisi Ketiga. Jakarta: Penerbit Erlangga.

Notoatmojo, Soekidjo. 2010. Promosi Kesehatan.Jakarta :Renika Cipta

Profil Dinas Kesehatan Kabupaten Tasikmalaya (2016)

Sulistyawati, Ari. 2009. Asuhan Kebidanan Pada Masa Kehamilan. Jakarta: Salemba Medika 